\title{
Antennal-Lobe Organization in Desert Ants of the Genus Cataglyphis
}

\author{
Sara Mae Stieb ${ }^{a}$ Christina Kelber ${ }^{a}$ Rüdiger Wehner ${ }^{b}$ Wolfgang Rössler ${ }^{a}$ \\ a Department of Behavioral Physiology and Sociobiology, Biocenter, University of Würzburg, Würzburg, Germany; \\ ${ }^{b}$ Brain Research Institute, University of Zürich, Zürich, Switzerland
}

\section{Key Words}

Ant $\cdot$ Antennal lobe $\cdot$ Cataglyphis $\cdot$ Glomerulus $\cdot$ Insects $\cdot$ Interspecific comparison - Macroglomerulus - Olfaction • Olfactory glomeruli $\cdot$ Plasticity

\begin{abstract}
Desert ants of the genus Cataglyphis possess remarkable visual navigation capabilities. Although Cataglyphis species lack a trail pheromone system, Cataglyphis fortis employs olfactory cues for detecting nest and food sites. To investigate potential adaptations in primary olfactory centers of the brain of $C$. fortis, we analyzed olfactory glomeruli (odor processing units) in their antennal lobes and compared them to glomeruli in different Cataglyphis species. Using confocal imaging and 3D reconstruction, we analyzed the number, size and spatial arrangement of olfactory glomeruli in C. fortis, C. albicans, C. bicolor, C. rubra, and C. noda. Workers of all Cataglyphis species have smaller numbers of glomeruli (198249) compared to those previously found in olfactory-guided ants. Analyses in 2 species of Formica - a genus closely related to Cataglyphis - revealed substantially higher numbers of olfactory glomeruli (c. 370), which is likely to reflect the importance of olfaction in these wood ant species. Comparisons between Cataglyphis species revealed 2 special features in C. fortis. First, with c. 198 C. fortis has the lowest num-
\end{abstract}

ber of glomeruli compared to all other species. Second, a conspicuously enlarged glomerulus is located close to the antennal nerve entrance. Males of $C$. fortis possess a significantly smaller number of glomeruli (c. 150) compared to female workers and queens. A prominent male-specific macroglomerulus likely to be involved in sex pheromone communication occupies a position different from that of the enlarged glomerulus in females. The behavioral significance of the enlarged glomerulus in female workers remains elusive. The fact that $C$. fortis inhabits microhabitats (salt pans) that are avoided by all other Cataglyphis species suggests that extreme ecological conditions may not only have resulted in adaptations of visual capabilities, but also in specializations of the olfactory system.

Copyright $\odot 2011$ S. Karger AG, Basel

\section{Introduction}

Desert ants of the genus Cataglyphis have become model systems for the study of animal navigation in general, and visually guided behavior in particular [Wehner, 2003]. While foraging they employ a path-integrating system [for a review, see Wehner and Srinivasan, 2003] including a skylight-based visual compass [Wehner and Müller, 2006] and a stride-integrating odometer [Witt-

\section{KARGER}

Fax +41613061234 E-Mail karger@karger.ch www.karger.com
(C) 2011 S. Karger AG, Basel

0006-8977/11/0773-0136\$38.00/0

Accessible online at:

www.karger.com/bbe
Sara Mae Stieb

Biocenter, Behavioral Physiology and Sociobiology, Zoology II

University of Würzburg, Am Hubland

DE-97074 Würzburg (Germany)

Tel. +49931 318 9581, E-Mail sara-mae.stieb@biozentrum.uni-wuerzburg.de 
linger et al., 2006] as their main navigational means. In addition, they use landmarks to define places and routes [Wehner and Räber, 1979; Collett et al., 1992; BischKnaden and Wehner, 2003; Collett and Collett, 2009]. Even though they establish quite pronounced individual sector fidelities, i.e. they leave the nest and return to it along familiar vectors or landmark-defined routes, during their foraging lives [Wehner et al., 2004], they do not use trail pheromones [Schmid-Hempel, 1983; Wehner et al., 1983], as it is the case in many other ant species [Hölldobler and Wilson, 1990]. However, they rely on chemical cues for pinpointing food sources [Wolf and Wehner, 2000]. Furthermore, in the vicinity of the nest, they can use olfactory landmarks for homing [Steck et al., 2009, 2010]. Ants, in general, employ a variety of olfactory signals in the context of sexual communication, nestmate recognition and caste discrimination, alarm or recruitment behavior, or trail marking. In fact, chemical communication is the most prominent type of social interactions among ants [Hölldobler and Wilson, 1990; Kleineidam and Rössler, 2009]. Therefore, the question arises whether the olfactory system of the visual navigator $\mathrm{Ca}$ taglyphis is specialized and/or adapted to the particular means of foraging and homing under the extreme ecological conditions of desert environments inhabited by Cataglyphis species.

In ants as in all insects, odor information is received via olfactory receptor neurons (ORNs) located in the olfactory sensilla on the antennae. The axons of ORNs project to the first olfactory neuropil, the antennal lobe (AL), and terminate in the functional units of the AL, the glomeruli [for reviews, see Homberg et al., 1989; Mustaparta, 1990; Hildebrand and Shepherd, 1997; Hansson and Anton, 2000; Kleineidam and Rössler, 2009; Galizia and Rössler, 2010]. In social Hymenoptera, the incoming axons of ORNs are sorted into several sensory tracts, which innervate different clusters of glomeruli [Kirschner et al., 2006; Zube et al., 2008; Kelber et al., 2010]. Excitation of ORNs by odors results in a spatial activation pattern of different glomeruli, e.g. in honeybees [Joerges et al., 1997; Galizia et al., 1999b; Sachse et al., 1999], Drosophila [Fishilevich and Vosshall, 2005], and in ants [Zube et al., 2008; Kuebler et al., 2010]. In several insect species, sex-pheromone-sensitive ORNs in males of moths [Anton and Homberg, 1999] or honeybee drones [Arnold et al., 1985; Sandoz, 2006], for example, send their projections to a single or to several enlarged glomeruli, the so-called macroglomeruli (MGs) or MG complexes (MGCs). In non-sexual individuals of leaf-cutting ants (Atta and Acromyrmex), an MG was found in large workers [Klein- eidam et al., 2005; Kelber et al., 2009], where it is involved in the detection and processing of trail pheromone components [Kuebler et al., 2010].

As in Cataglyphis behavioral studies have shown that olfactory cues are used during various phases of the ants' foraging journeys [Wolf and Wehner, 2000, 2005; Steck et al., 2009, 2010], we inquired about potential adaptations in the primary olfactory centers of Cataglyphis. In particular, we investigated the glomerular organization of the AL of 5 species of Cataglyphis by focusing on the number, size, and spatial arrangement of the olfactory glomeruli. We addressed the question of whether differences in microhabitats and resulting variances in foraging strategies (e.g. lengths of outbound runs) have led to adaptations in the olfactory system of different Cataglyphis species inhabiting different desert environments (steppe-like, sandy, or salt pan areas). In particular, $C$. fortis is endemic to the salt flats of western North Africa, which are completely avoided by other Cataglyphis species [Wehner, 1983]. The utilization of such a specialized habitat results in outstanding traits, e.g extremely large foraging ranges [Wehner, 1987] and high nest-site stabilities [Dillier and Wehner, 2004], compared to other Cataglyphis species. In fact, C. fortis shows an enlarged glomerulus near the AL entrance that is absent in other Cataglyphis species. Hence, the AL structure of $C$. fortis workers is analyzed in more detail. Furthermore, we compare the number and size of glomeruli in different $C$. fortis castes (workers, queens, and males). Finally, we include 2 species of the wood ant Formica, which inhabits mesic environments and employs trail pheromone recruitment. Even though ecologically different from Cataglyphis, Formica is phylogenetically very closely related to Cataglyphis, as both genera belong to the same subfamily of ants (Formicinae) and even to the same tribe (Formicini).

\section{Materials and Methods}

\section{Animals}

In total 5 Cataglyphis species and 2 Formica species were compared regarding their AL anatomy: C. fortis (Forel, 1902), C. albicans (Roger, 1859), C. bicolor (Fabricius, 1793), C. rubra (Forel, 1903), C. noda (Brullé, 1832), F. sanguinea (Latreille, 1798), and F. rufibarbis (Fabricius, 1793). Workers and males/females of C. fortis were collected in a salt pan near Menzel Chaker (348580N/108250E), and workers of C. albicans, C. rubra, and C. bicolor were obtained from shrubby habitats around the salt pan as well as near Mahares (343149N/102949E), Tunisia, in July 2007 and July 2010. Workers of C. noda came from the southern Peloponnese (370166N/222639E), Greece (collected in June 2007). 
All Cataglyphis ants were either transferred alive to the Biocenter of the University of Würzburg, or dissection and fixation of the brains were conducted on-site. The phylogenetic relationships between the Cataglyphis species examined in the present account are depicted in figure 1.

Workers of F. rufibarbis and F. sanguinea were collected in the surroundings of the Biocenter of the University of Würzburg (494644N, 95817E) in April 2010.

\section{Neuroanatomical Procedures}

For $3 \mathrm{D}$ reconstruction of single glomeruli in the $\mathrm{AL}$, all brains were treated as described in the following: the ants were anesthetized with $\mathrm{CO}_{2}$, decapitated, and the head capsules were fixed in dental-wax-coated dishes. The head capsule was covered with fresh ant saline solution $\left(127 \mathrm{mM} \mathrm{NaCl}, 7 \mathrm{mM} \mathrm{KCl}, 1.5 \mathrm{mM} \mathrm{CaCl}_{2}\right.$, $0.8 \mathrm{mM} \mathrm{Na}_{2} \mathrm{HPO}_{4}, 0.4 \mathrm{mM} \mathrm{KH}_{2} \mathrm{PO}_{4}, 4.8 \mathrm{mM}$ TES, and $3.2 \mathrm{mM}$ trehalose, $\mathrm{pH}$ 7.0) and opened by cutting a square window in-between the compound eyes. Glands and tracheae were gently removed, and the brains were dissected and fixed immediately in ice-cold Fix-Mix (2\% paraformaldehyde/2\% glutaraldehyde) in phosphate-buffered saline (PBS, $\mathrm{pH}$ 7.2) and stored for 3-30 days in the fridge. This fixation leads to increased autofluorescence which, compared to formaldehyde fixation only, allowed us to better identify the outlines of glomeruli [Kelber et al., 2009]. The brains were then rinsed in PBS $(3 \times, 10 \mathrm{~min})$, dehydrated in an ascending series of ethanol $(50,70,80,90,95$, and $3 \times 100 \%, 10$ min each), and finally transferred into methylsalicylic acid (M2047; Sigma-Aldrich, Steinheim, Germany).

To trace the sensory tracts of antennal ORN axons subdividing the AL glomeruli into clusters and later localize these clusters, anterograde stainings of the antennal nerve were conducted in $C$. fortis workers $(\mathrm{n}=2)$. The ants were immobilized in a plexiglass holder, and 1 antenna was cut off at the base of the scapus. A droplet of tetramethylrhodamine dextran with biotin ('micro-ruby', D-7162; Molecular Probes, Eugene, Oreg., USA) dissolved in distilled water was applied in a ring of wax on the cut base and left in place for $1 \mathrm{~h}$. After staining, workers were allowed to move freely for $4 \mathrm{~h}$ before the brains were dissected in saline solution followed by fixation with $4 \%$ paraformaldehyde in PBS (pH 7.2) and dehydration as described above.

To visualize the synaptic neuropil in individual glomeruli in more detail at higher magnification, preparations were doubly labeled with an antibody to synapsin and f-actin-phalloidin staining (methods according to Rössler et al. [2002]). Brains were dissected, fixed in cold $4 \%$ formaldehyde in PBS (pH 7.2) overnight, and sectioned at $100 \mu \mathrm{m}$ thickness with a vibrating microtome (Leica VT 1000S; Leica, Nussloch, Germany). Afterwards, they were simultaneously incubated in Alexa Fluor 488 phalloidin (A12379; Molecular Probes) and in monoclonal antibody to the Drosophila synaptic-vesicle-associated protein synapsin I (1:50, SYNORF1, kindly provided by E. Buchner, University of Würzburg) followed by incubation in Alexa-Fluor-568-conjugated goat anti-mouse secondary antibody (1:250, A11004; Molecular Probes); precise descriptions have been published by Rössler et al. [2002]; Groh et al. [2004], and Stieb et al. [2010].

Laser Scanning Confocal Microscopy, 3D Reconstruction, and Data Analysis

Confocal images and image stacks were taken at a resolution of $1,024 \times 1,024$ pixels and an optical thickness of $1 \mu \mathrm{m}$ from the

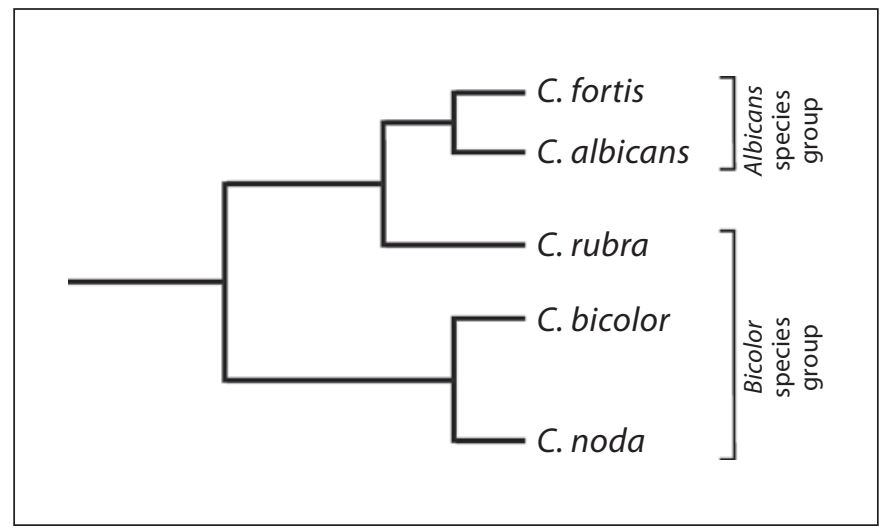

Fig. 1. The cladogram is based on morphometric data (male sexual organs [Agosti, 1990] and worker characteristics [Radchenko, 2001]) as well as molecular phylogentic analyses [Knaden et al., in prep.]. In all these studies, the bicolor species group and the albicans species group appear as sister taxa. Within the albicans species group, C. fortis (Forel, 1902) and C. rubra (Forel, 1903) have originally been classified as subspecies of $C$. albicans, and were raised to species rank only much later (C. fortis [Wehner 1983] and C. rubra independently by Collingwood [1985] and Wehner [1986]). While in the steppe-like arid zones of North Africa C. albicans and C. rubra occur sympatrically [Dillier and Wehner, 2004], C. fortis - the species that is most closely related to C. albicans [Wehner, 1983] - is endemic to the salt pan areas of Tunisia and Algeria [Wehner et al., 1994].

ALs in whole-mount preparations using a laser-scanning confocal microscope (Leica TCS SP2 AOBS, $20 \times 0.7 \mathrm{NA}$ and $63 \times 1.20$ NA lens; Leica Microsystems AG, Wetzlar, Germany). 3D software (AMIRA 3.1.1; Mercury Computer Systems, Berlin, Germany) was used for reconstruction of individual glomeruli within the $\mathrm{AL}$, sensory tracts, and the antennal nerve (AN). The total number and volume of all glomeruli were assessed by complete $\mathrm{AL}$ reconstructions in 17 ants in total (C. fortis: workers $\mathrm{n}=4$; males $\mathrm{n}=2$, and queens $\mathrm{n}=2$; C. albicans: workers $\mathrm{n}=3$; C. bicolor: workers $\mathrm{n}=1$; C. noda: workers $\mathrm{n}=1$; C. rubra: workers $\mathrm{n}=1 ;$ F. sanguinea: workers $\mathrm{n}=2$, and F. rufibarbis: workers $\mathrm{n}=1$; table 1). Additional Cataglyphis specimens were analyzed by visual inspection.

In order to compare the size of glomeruli between different ALs and due to the fact that the number and size of glomeruli in the AL varied considerably between the investigated species, we used a relative measurement of the glomerular volume. Therefore, the median (all data were not normally distributed: KolmogorovSmirnov procedure, $\mathrm{p}<0.05$ ) of all glomerular volumes was calculated for each AL to subsequently compute the ratio of the volume of each glomerulus and the median volume (method modified after Kelber et al. [2009]). This normalized volume describes how many times bigger a single glomerulus is compared to the median size of all glomeruli. Boxplots were used to illustrate the normalized volume values of all glomeruli within $1 \mathrm{AL}$ (fig. 2). Outliers were defined as cases with values that are $1.5-3$ box 
Table 1. Information on the investigated Cataglyphis and Formica species, and their AL characteristics determined in this study

\begin{tabular}{|c|c|c|c|c|c|c|c|}
\hline $\begin{array}{l}\text { Genus } \\
\text { (common name) }\end{array}$ & Species & $\begin{array}{l}\text { Country } \\
\text { of origin }\end{array}$ & Habitat & $\begin{array}{l}\text { Caste } \\
\text { (n) }\end{array}$ & $\begin{array}{l}\text { Glo. } \\
\mathrm{n}\end{array}$ & $\begin{array}{l}\mathrm{Vol}_{\min } \\
\mu \mathrm{m}^{3}\end{array}$ & $\begin{array}{l}\mathrm{Vol}_{\text {max }} \\
\mu \mathrm{m}^{3}\end{array}$ \\
\hline \multirow[t]{7}{*}{ Desert ant } & \multirow[t]{3}{*}{ C. fortis } & \multirow[t]{6}{*}{ Tunisia } & \multirow[t]{3}{*}{ salt pan } & w (4) & $198 \pm 7$ & 424 & 42,683 \\
\hline & & & & $\mathrm{m}(2)$ & $150 \pm 2$ & 672 & 90,342 \\
\hline & & & & $\mathrm{q}(2)$ & $219 \pm 3$ & 1,027 & 21,302 \\
\hline & C. albicans & & \multirow[t]{4}{*}{ low-shrub area } & $\mathrm{w}(3)$ & $226 \pm 4$ & 586 & 13,171 \\
\hline & C. bicolor & & & $\mathrm{w}(1)$ & 249 & 503 & 25,582 \\
\hline & C. rubra & & & $\mathrm{w}(1)$ & 249 & 436 & 14,915 \\
\hline & C. noda & Greece & & $\overline{\mathrm{w}(1)}$ & 226 & 1,542 & 38,488 \\
\hline \multirow[t]{2}{*}{ Wood ant } & F. rufibarbis & \multirow{2}{*}{ Germany } & grassland & $\mathrm{w}(1)$ & 373 & 538 & 7,608 \\
\hline & F. sanguinea & & grassland & $\mathrm{w}(2)$ & $372 \pm 1$ & 403 & 9,858 \\
\hline
\end{tabular}

Genus (common name)/species = Analyses of the AL structure were performed for the listed desert ant (Cataglyphis) and wood ant (Formica) species; country of origin and habitat = description of the locality where ants were collected; caste (n) = belonging to the nonsexual (w: worker) or sexual (q: queen; m: male) caste (number of 3D-reconstructed ALs); Glo. = mean $\pm \mathrm{SD}$ of glomeruli found in the AL; $\mathrm{Vol}_{\text {min }}=$ volume of the smallest glomerulus; $\mathrm{Vol}_{\max }=$ volume of largest glomerulus.

lengths, extreme values (with the largest glomerulus termed 'enlarged glomerulus') as cases with values $>3$ box lengths distant from the upper and lower margins of the box, whereas the length of the box equals 1 interquartile range. All descriptive statistical analyses were performed with SPSS 18.0 software (SPSS, Chicago, Ill., USA).

\section{Results}

\section{Number of Glomeruli}

In the non-sexual caste of the 5 Cataglyphis species tested in this account, the average number of glomeruli in the AL was lowest in C. fortis (198 \pm 7 glomeruli; table 1). In workers of C. albicans and C. noda, the $3 \mathrm{D}$ reconstructions revealed about 226 glomeruli, while $C$. $b i$ color and C. rubra workers had maximal numbers, namely 249 glomeruli. Compared to workers, males of $C$. fortis had a reduced number of $150 \pm 2$ glomeruli, whereas $C$. fortis queens had a slightly higher number of $219 \pm 3$ glomeruli. In comparison to the 2 Formica species (about 370 glomeruli), all tested Cataglyphis species had a smaller number of glomeruli.

\section{Size of Glomeruli}

In workers of all Cataglyphis species, the size of the glomeruli ranged from 424 to $42,683 \mu \mathrm{m}^{3}$. The difference between the smallest and the largest glomeruli (table 1) was the highest in C. fortis (see numbers given above). With respect to the normalized glomerular volumes, all workers of the Cataglyphis and Formica species showed several outliers. Extreme values were found in workers of all species with the exception of $C$. noda. Among the Cataglyphis workers, C. fortis possessed the biggest singular glomerulus (up to 7.2 times bigger) compared with the median size of all glomeruli within $1 \mathrm{AL}$ (fig. 2).

In the sexual castes of $C$. fortis, the size ranges of glomerular volumes were smaller for queens $(1,027-21,302$ $\left.\mu \mathrm{m}^{3}\right)$ and largest for males (672-90,342 $\mu \mathrm{m}^{3}$; table 1). Regarding the normalized volumes, $C$. fortis queens exhibited extreme values (besides several outliers) that lay within the range of those of the worker caste (fig. 2). In contrast, the extreme values of $C$. fortis males were up to 21.6 times larger than the median size of all glomeruli (again besides several outliers; fig. 2). These severely enlarged male-specific glomeruli are termed MGs in the following (using the criteria described by Kelber et al. [2009]).

\section{Position of Enlarged Glomeruli}

The largest glomerulus within $1 \mathrm{AL}$ (as defined by the criteria mentioned in the Materials and Methods section and termed 'enlarged glomerulus'; fig. 2) could be well localized in the 3D reconstructions (fig. 3). All enlarged glomeruli in workers of C. rubra and C. bicolor as well as 


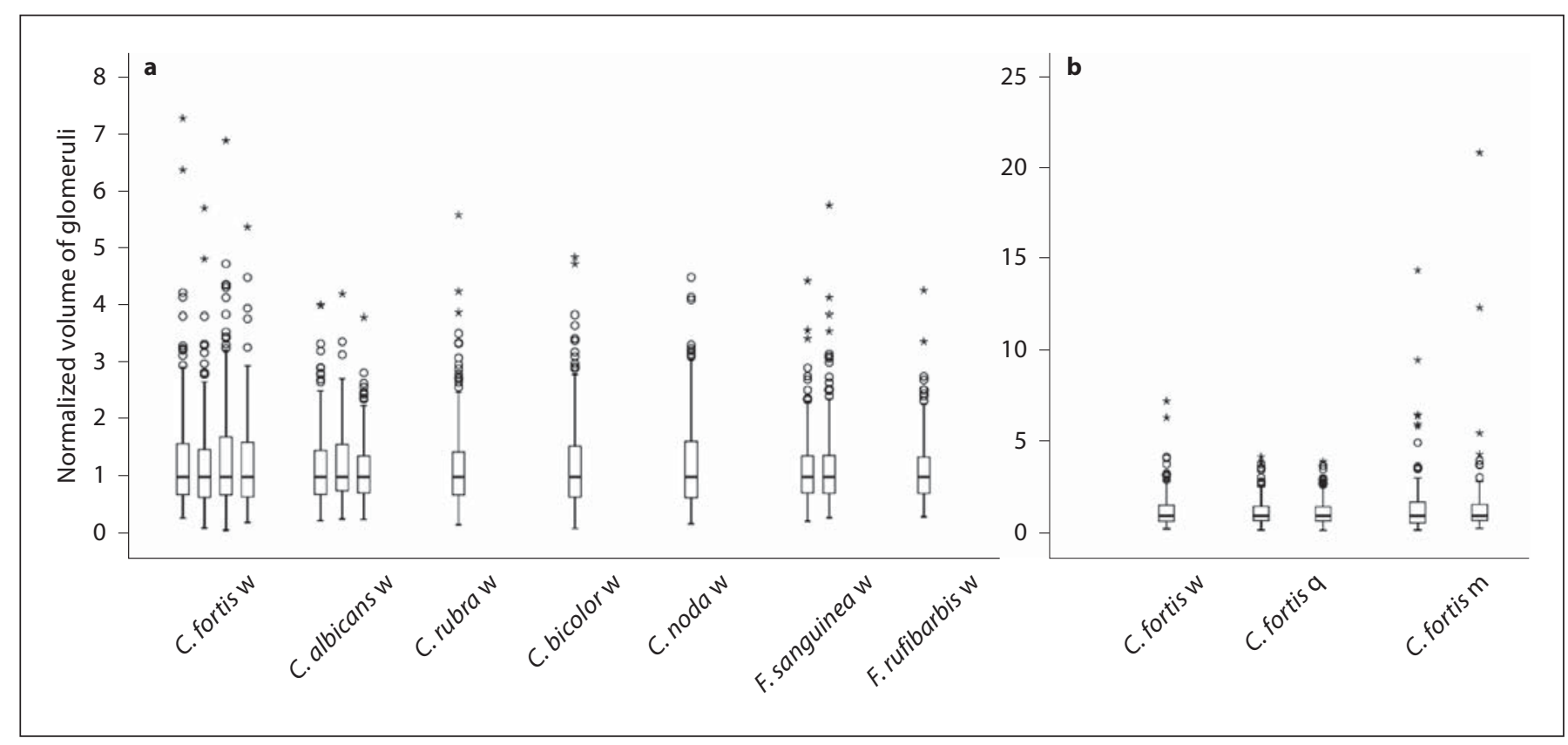

Fig. 2. Descriptive statistics for the identification of enlarged glomeruli in all Cataglyphis and Formica species. Boxes illustrate the median and variance of all normalized glomerular volumes. Extreme values are displayed as asterisks, outliers as open circles, and corresponding glomeruli are visualized in figure 3. a Normalized volumes of glomeruli in different Cataglyphis and For- mica workers (w). In all species, the AL comprises glomeruli identified as outliers and extreme values (with the exception of $C$. noda). b Normalized volumes of glomeruli in different $C$. fortis castes: worker (w), queen (q), and male (m). Females and males possess extreme values 4.0-7.2 and 14.4-21.6 times larger, respectively, than the median size of all glomeruli. the enlarged glomeruli of 2 C. albicans workers were located in a group of glomeruli occupying the dorsalmost part of the AL. In the 3rd C. albicans worker, the enlarged glomerulus was located near, but not directly at, the entrance of the AN. In all C. fortis specimens, the largest glomeruli of the workers were located at the same position close to the entrance of the AN (fig. 3a; enlarged glomerulus; yellow). F-actin phalloidin and anti-synapsin labeling confirmed the existence of a glomerulus containing very large synaptic neuropil located directly adjacent to the AN (fig. 4b). Anterograde mass stainings of ORN axons demonstrated that the enlarged glomerulus at the AN entrance is innervated by a high number of ORN axons (fig. 4 b, c). Figure $4 \mathrm{c}$ clearly shows that all other glomeruli in the same focal plane are less innervated than the enlarged glomerulus. The remaining glomeruli of $C$. fortis workers with extreme values were located either in the already mentioned dorsalmost part of the AL or more laterally.

In $C$. fortis queens, the largest glomerulus was located in a position corresponding to that of $C$. fortis workers, i.e. close to the AN entrance (fig. $3 \mathrm{~b}$ ). In both $C$. fortis males, the largest glomerulus was found medial to the
AN with 1 normal-sized glomerulus in between the AN entrance and the largest glomerulus (fig. 3c). The other glomeruli identified as extreme values of both males and queens were located in different positions in the AL. We would also like to mention 2 glomeruli identified as extreme values which in males are located at the dorsalmost part of the AL, near the dorsal lobe (DL).

In both Formica species, all enlarged glomeruli were found in different locations in the AL even within the same species.

\section{Sensory Tracts in C. fortis}

Mass labeling of ORN axonal projections allowed the classification of sensory-tract-specific glomerular clusters. The cluster classification was done for 2 C. fortis workers: 1 by using 3D reconstruction and 1 by performing careful visual inspection. Figure $4 \mathrm{c}$ shows a confocal image with the enlarged glomeruli clearly visible, while figure $4 \mathrm{~d}$ provides the corresponding $3 \mathrm{D}$ reconstruction. In $C$. fortis workers, the ORN axons form 4 distinct sensory tracts (T1-T4) innervating 4 characteristic clusters of glomeruli within the AL. In the following, these glo- 


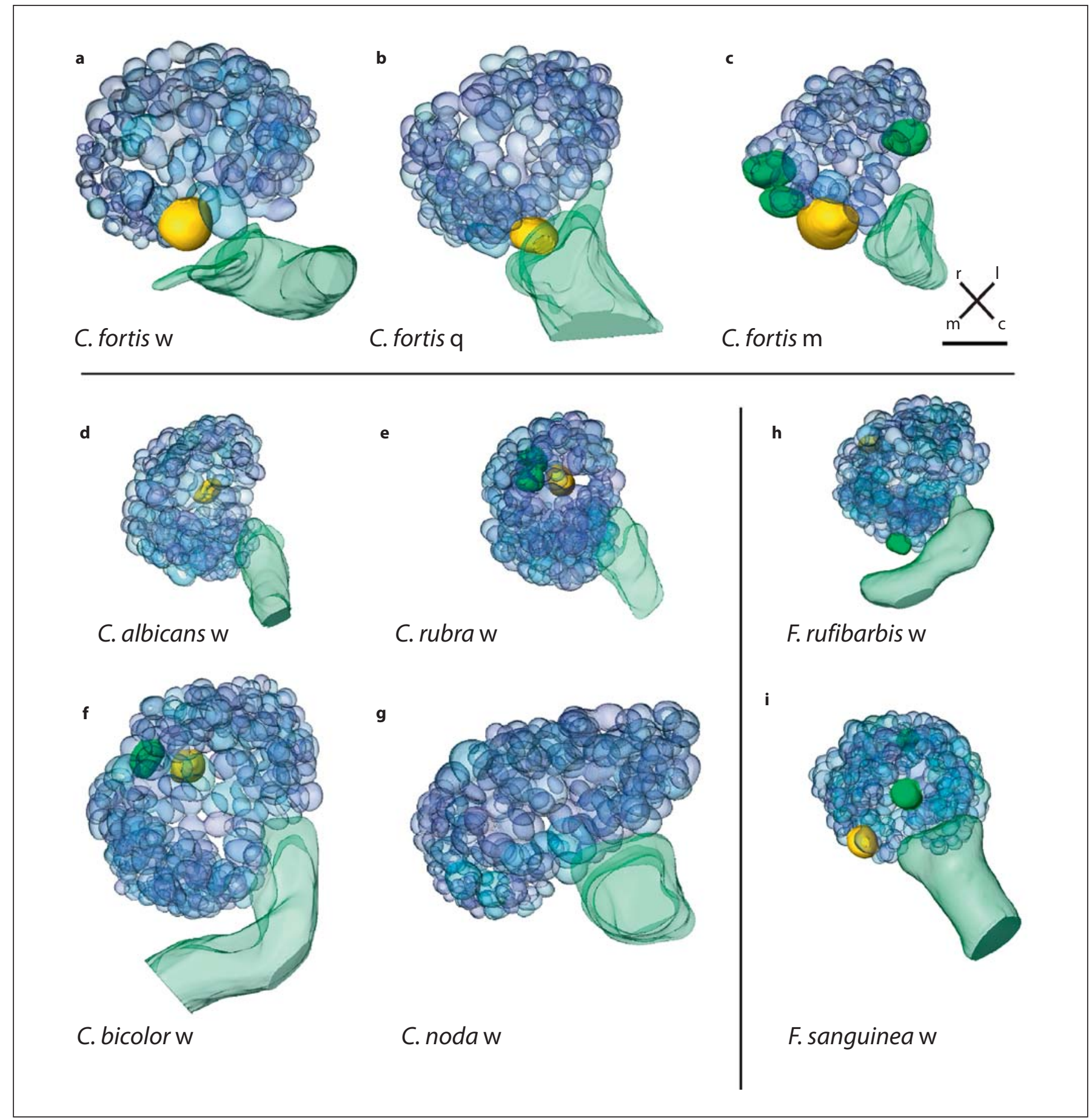

Fig. 3. AL reconstructions in Cataglyphis and Formica species. In all illustrations, the AN is outlined transparently, the largest glomerulus (if identified as an extreme value; fig. 2) is colored in yellow, further glomeruli classified as extreme values (fig. 2) are colored in green, and the remaining glomeruli, including outliers (fig. 2), in transparent blue. a-c 3D reconstructions of AL glomeruli in a $C$. fortis worker $(\mathrm{w} ; \mathbf{a})$, queen $(\mathrm{q} ; \mathbf{b})$ and male $(\mathrm{m} ; \mathbf{c})$ Whereas in females the largest glomerulus is located next to the AN entrance, the MG in males is located medial to the AN with one normal-sized glomerulus in between the AN entrance and itself. $\mathbf{d}-\mathbf{g} 3 \mathrm{D}$ reconstructions of AL glomeruli in workers of $C$. albicans (d), C. rubra (e), C. bicolor (f), and C. noda (g). All enlarged glomeruli are located at the dorsalmost part in the AL. $\mathbf{h}, \mathbf{i} 3 \mathrm{D}$ reconstructions of AL glomeruli in workers of $F$. rufibarbis (h) and F. sanguinea (i). Directions are indicated in the coordinate planes: $\mathrm{r}=$ rostral; $\mathrm{c}=$ caudal; $\mathrm{m}=$ medial; $\mathrm{l}=$ lateral. Scale bar: a-i $50 \mu \mathrm{m}$. 
Fig. 4. Anatomy of the AL and the division of the AN into sensory tracts in C. fortis workers. a, c The position of the enlarged glomerulus (indicated with an arrow in ad) next to the AN entrance is clearly visible. a Single optical section showing the $\mathrm{AN}$ and the enlarged glomerulus next to it. b Immunolabeling of the AL neuropil. The enlarged glomerulus is clearly defined by its postsynaptic sides visualized by the phalloidin-labeled f-actin (labeled in green) and the presynaptic input stained with an antibody to synapsin (labeled in red). c Confocal image of the AL with an anterogradely labeled AN showing the sensory innervation of AL glomeruli. In comparison to all other glomeruli in this sectional plane, the enlarged glomerulus is innervated by a large number of axons from ORNs. Based on these backfill stainings, the sensory tracts and the resulting partitioning in glomerular clusters of tract-associated glomeruli were reconstructed (d). d Ventral and dorsal views of $3 \mathrm{D}$ reconstructions of sensory tracts and associated glomerular clusters. Four sensory tracts innervate 4 glomerular clusters (T1 cluster with 37 glomeruli: blue; T2 cluster with 69 glomeruli: green; T3 cluster with 85 glomeruli: red; T4 cluster with 18 glomeruli: yellow) in the AL. The enlarged glomerulus belongs to the T3 cluster. Dorsal tract: transparent blue. Directions are indicated in the coordinate planes: $\mathrm{r}=$ rostral; $c=$ caudal; $\mathrm{m}=$ medial; $1=$ lateral. Scale bars $=50 \mu \mathrm{m}(\mathbf{a}, \mathbf{c}, \mathbf{d})$ and $20 \mu \mathrm{m}(\mathbf{b})$.
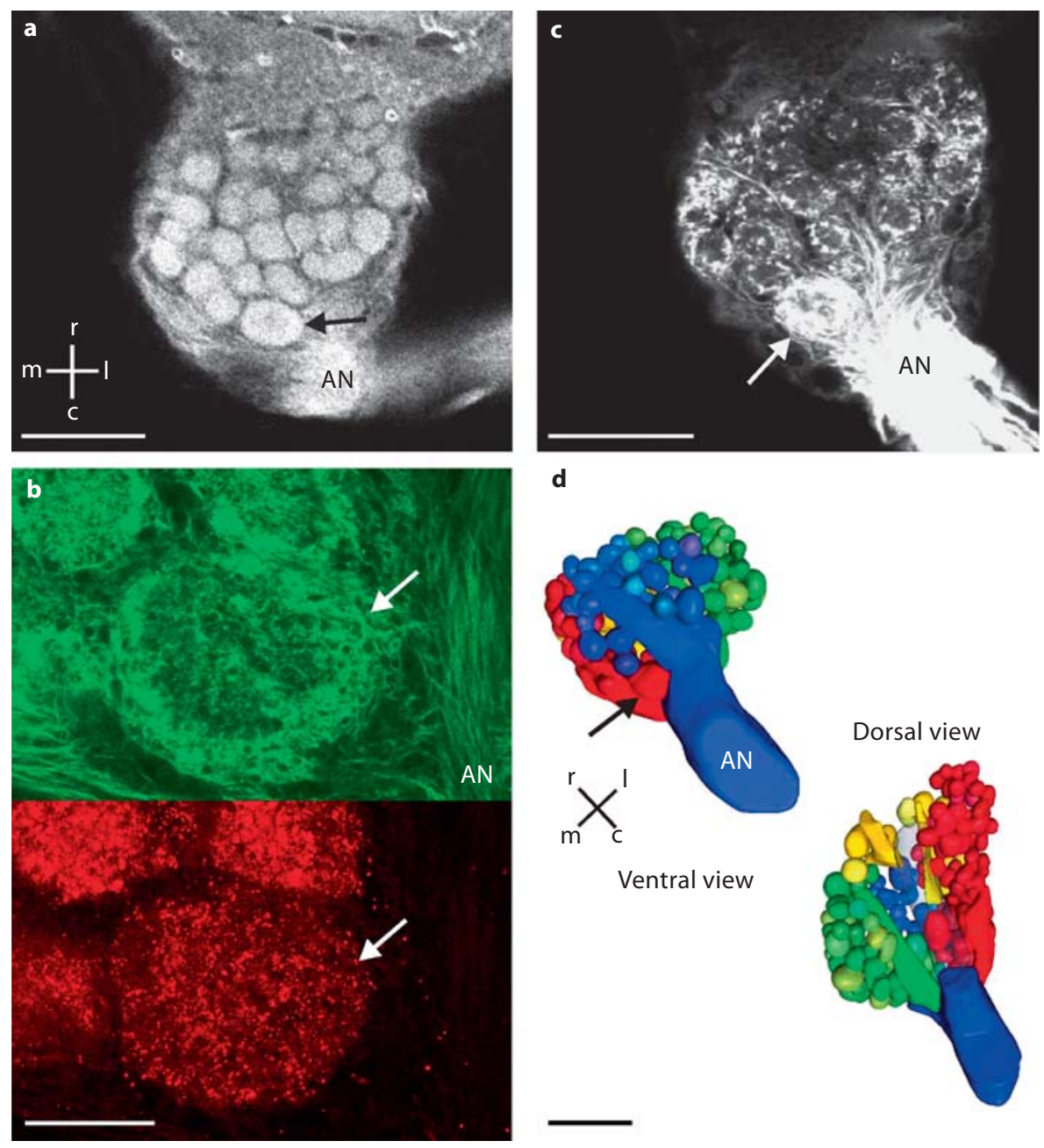

d

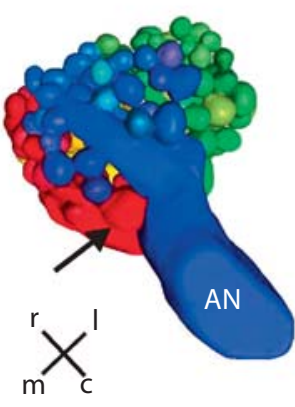

Ventral view

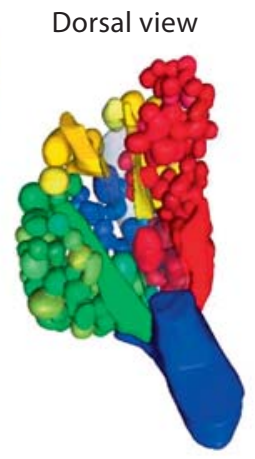

merular subregions are termed T1-T4 clusters (fig. 4d). $\mathrm{T} 1$ proceeds at the ventral surface of the AL and innervates 37 glomeruli of the T1 cluster (blue glomeruli in fig. $4 \mathrm{~d}$ ) located on the ventral part of the AL flanked laterally by the T2 (green glomeruli in fig. 4d) and medially by the T3 (red glomeruli in fig. $4 \mathrm{~d}$ ) cluster. The T2 cluster comprises 69 glomeruli spreading along the lateral side of the AL from ventral to dorsal. Similarly, the medial-situated $\mathrm{T} 3$ cluster disperses from ventral to dorsal and comprises the highest number of glomeruli (85 glomeruli). Next to the AN, this cluster contains the enlarged glomerulus, whereas the dorsal part of this cluster consists of a high number of small glomeruli. Only 18 glomeruli form the T4 cluster (yellow glomeruli in fig. 4d) located on the dorsalmost $\mathrm{AL}$ region near the DL. In contrast to the ORNs of sensory tracts T1-T3, the ORNs of the T4 subpopulation innervate not only the cortical layer but also the entire glomerulus, being similar to findings in the honeybee [Arnold et al., 1985]. One tract, from which the $\mathrm{T} 4$ tract is emerging, projects toward the DL.

\section{Discussion}

\section{Intraspecific Variations in the Number of Glomeruli} in $\mathrm{C}$. fortis

Many insect species exhibit caste- and sex-specific variations in general features of the ALs. The behavioral repertoires of hymenopteran males are in general restricted, which in turn results in a reduced number of glomeruli compared to females (Apis mellifera [Arnold et al., 1985; Brockmann and Brückner, 2001; Sandoz, 2006]; Harpegnathos saltator [Hoyer et al., 2005]; Camponotus floridanus [Zube and Rössler, 2008]; Camponotus ja- 
ponicus [Nishikawa et al., 2008], and Atta vollenweideri [Kuebler et al., 2010]). Analyses of the number of glomeruli in $C$. fortis males confirm these findings. Within the female caste, $C$. fortis queens have a higher number of glomeruli than workers and males. Other studies in ants showed that the number of glomeruli in queens exceeded that in males, but was still lower or comparable to the numbers found in workers (A. vollenweideri [Kuebler et al., 2010]; A. mellifera [Groh and Rössler, 2008]; C. japonicus [Nishikawa et al., 2008], and C. floridanus [Zube and Rössler, 2008]). That this ratio is reversed in C. fortis might most likely be due to the especially low number of glomeruli in the workers rather than to a relatively larger number of glomeruli in the queens.

\section{Interspecific Variations in the Number of Glomeruli}

With a mean of 198 glomeruli, C. fortis has by far the lowest glomerular number among all Cataglyphis species tested in this account (see table 1: from 198 glomeruli in C. fortis to 249 glomeruli in C. rubra and C. bicolor). Compared to other hymenopteran species (156-166 glomeruli in the honeybee [Arnold et al., 1985; Flanagan and Mercer, 1989; Galizia et al., 1999a; Kirschner et al., 2006] and 186-198 glomeruli in 2 parasitoid wasps [Smid et al., 2003]), ant workers in general have a higher number of glomeruli per AL: the highly olfactory fungus-growing ant species possess 257-630 glomeruli [Kelber et al., 2009; Kuebler et al., 2010]; likewise, the group-recruiting and trail-following carpenter ants [Haak et al., 1996] also have high glomerular numbers (430 glomeruli in C. japonicus [Nishikawa et al., 2008] and 434 glomeruli in C. floridanus [Zube and Rössler, 2008]). Formica species, which have been tested in this account, perform chemical recruitment [Hölldobler and Wilson, 1990] which nicely correlates with high numbers of about 370 glomeruli in the 2 tested species (table 1). In contrast to all the ant species mentioned above, Cataglyphis ants forage solitarily and do not use trail pheromones, but rely primarily on visual guidance mechanisms [Wehner, 2003].

The interspecific variations in glomerular numbers indicate that the number of glomeruli appears to be generally correlated with the amount of chemically mediated behaviors. Ant species with a pronounced olfactoryguided behavior like the use of a trail pheromone have a high glomerular number [Kleineidam and Rössler, 2009]. The results in Cataglyphis indicate that species relying more on visual cues may possess a reduced glomerular number. This hypothesis is further supported by a small number of glomeruli in the Namibian desert ant (223 glomeruli [Wenzler, pers. commun.]), which in contrast to Cataglyphis occasionally exhibits a particular kind of recruitment behavior [Marsh, 1985; Wehner, 1987]. In the same way, Gigantiops destructor, which is characterized by huge compound eyes and impressive capabilities of visually detecting moving objects and navigating by visual means [Hölldobler and Wilson, 1990, pp. 259; Gronenberg and Hölldobler, 1999; Beugnon et al., 2001], as well as the mostly visually guided ponerine ant $H$. saltator have low numbers of glomeruli (250 glomeruli in G. destructor [Kelber, pers. commun.]; 200 glomeruli in Formica pratensis [Goll, 1967], and around 177 glomeruli in H. saltator [Hoyer et al., 2005]).

The assumed correlation between a reduced glomerular number in C. fortis and the largely visually guided behavior of this species goes along with comparative studies among different ant species showing that Cataglyphis has not only relatively large optic lobes, but also possesses an exceedingly large collar - the visual input region of the learning- and memory-associated mushroom bodies [Gronenberg and Hölldobler, 1999; KühnBühlmann and Wehner, 2006].

\section{Clusters of Glomeruli in C. fortis Workers}

In C. fortis workers, the AN is divided into several sensory tracts of which 4 innervate the AL glomeruli. The grouping of glomeruli into a variable number of clusters is a common feature in Hymenoptera and allows for interspecific comparisons and potential phylogenetic inferences. In the honeybee, there are 4 glomerular clusters as in C. fortis [Arnold et al. 1985; Flanagan and Mercer, 1989; Galizia et al., 1999a; Kirschner et al., 2006], but 6 and 7 sensory tracts innervate the AL glomeruli in the ants $A$. vollenweideri [Kelber et al., 2010] and C. floridanus [Zube et al., 2008] as well as C. japonicus [Nakanishi et al., 2010], respectively. The reduced number of glomerular clusters in C. fortis compared to other ant species correlates with the small number of glomeruli and might be indicative of the importance of vision rather than olfaction in this species.

The MG in C. fortis Males and Its Possible Function

A sexual dimorphism in the AL structure based on sex pheromone communication is reported for a number of insect species [for review, see Rospars, 1988; Galizia and Rössler, 2010]. The occurrence of an MG or an MGC always located near the AN entrance and exclusively receiving input from sex-pheromone-sensitive ORNs has been described for males of several insect species, e.g. moths [Hansson et al., 1991; Anton and Homberg, 1999; Rössler et al., 1999] and honeybees [Arnold et al., 1985; Sandoz, 2006]. The increased size of MGs results from a 
high number of terminating ORNs [Vickers and Baker, 1997; Berg et al., 1998]. Similarly, in males of several ant species, enlarged glomeruli have been described (H. saltator [Hoyer et al., 2005]; A. vollenweideri [Kuebler et al., 2010], and C. japonicus [Nakanishi et al., 2010]), but their specific involvement in sex pheromone communication remains to be elucidated.

An MG near the AN entrance was also found in the males of $C$. fortis. The MG location differs from that of the enlarged glomeruli found in the female castes. Due to the fact that this MG was only found in C. fortis males, it is likely that sex pheromone detection plays a prominent role for the male during courtship and mating behavior. In some Cataglyphis species, it has been shown that the males respond to the sexual 'calling behavior' of potentially pheromone-emitting females (C. iberica [Cerdá, 1988]; C. cursor [Lenoir et al., 1988], and C. savignyi [Wehner and Wehner, unpubl. data]).

\section{Enlarged Glomeruli in the Different Cataglyphis}

Species and Their Possible Functions

With only one exception, all enlarged glomeruli in the workers of C. rubra, C. bicolor and C. albicans are located in a group of glomeruli constituting the dorsalmost part of the AL nearest to the DL. Analyses of the sensory tracts in C. fortis revealed that these glomeruli belong to the T4 cluster. Based on the conspicuous position of this dorsalmost cluster of glomeruli and the fact that some of these glomeruli are enlarged in all tested Cataglyphis species, we assume that the corresponding glomeruli in all Cataglyphis workers belong to the T4 cluster and might be involved in the processing of $\mathrm{CO}_{2}$, thermo- or hygroreceptive information. In a corresponding region of the $\mathrm{AL}, \mathrm{a} \mathrm{CO}_{2}-$ sensitive glomerulus has been described for several moth species [Bogner et al., 1986; Kent et al., 1986; Lee and Altner, 1986; Kent et al., 1999; Guerenstein et al., 2004], and thermo- and hygroreceptive glomeruli were identified in cockroaches, honeybees, and carpenter ants [Nishikawa et al., 1995; Nishino et al., 2003, 2009; Nakanishi et al., 2010].

In C. fortis workers, the largest glomerulus is located next to the AN entrance. An MG not involved in the processing of sex pheromone information was discovered for the first time in leaf-cutting ants [Kleineidam et al., 2005]. There the MG is found only in large workers and is located close to the AN. Physiological as well as anatomical studies indicate that this MG is involved in the detection and processing of trail pheromone components [Kleineidam et al., 2005; Kelber et al., 2009, 2010; Kuebler et al., 2010]. These studies clearly demonstrate that the occurrence of enlarged glomeruli or even MGs may vary sub- stantially across ant species and even within the same species, and may correlate with certain behavioral requirements of odor processing. Despite the fact that the enlarged glomerulus of $C$. fortis workers does not fulfill all the criteria of an MG (if we use the criteria used for defining an MG by Kelber et al. [2009]), its size, stable location among tested workers, and its absence in all other tested Cataglyphis species indicate a specialized function of this glomerulus. As the backfill stainings clearly show that the enlarged glomerulus receives an increased input from ORN axons (fig. 4c), it is very likely that this glomerulus serves a particular and unique function that may be related to the extreme habitat in this species.

If we now recall that $C$. fortis possesses the AL with the lowest number of glomeruli among all tested Cataglyphis species and assume that the number of glomeruli reflects the complexity of olfactory-guided behavior, why is it that of all Cataglyphis species just C. fortis has an enlarged glomerulus at its AN entrance? Physiological (in particular functional imaging) studies are needed to characterize the odor specificity of the enlarged glomerulus. The fact that the enlarged glomerulus in the AL entrance of $C$. fortis is absent in the AL of the most closely related C. albicans (fig. 1) may indeed indicate that this glomerulus represents an adaptation to the special behavioral ecology of $C$. fortis, which among all its congeners takes an outstanding position regarding its preferred habitat, the food-impoverished salt pan flats of the Algerian and Tunisian chotts and sebkhas [Wehner, 1981, 1983; Wehner et al., 1994]. The North African C. bicolor, C. albicans and C. rubra inhabit the nutritionally richer low-shrub semi-deserts surrounding the salt pans [Dillier and Wehner, 2004]. To unravel which of the many differences in the behavioral ecology between $C$. fortis and its congeners [Schmid-Hempel, 1983; Wehner, 1983, 1987; Dillier and Wehner, 2004] are functionally related to the presence of the remarkably enlarged glomerulus in C. fortis remains a challenging task to accomplish.

\section{Acknowledgments}

We thank Nils Becker, Anna Hellwig, and Nadine Wenzler for providing valuable assistance during the field work in Tunisia and together with Linda Kuebler, Marieluise Obermayer and AnneKristin Wagner for their help with brain preparations and/or 3D reconstructions. We also thank Markus Knaden, Kathrin Steck and Sebastian Schwarz for providing us with Cataglyphis specimens. We thank the Graduate School of Life Sciences, University of Würzburg, for support (S.M.S. is an associated member). Funding was obtained from the German Research Foundation [DFG SFB 554 (A8) to W.R.], a woman grant (to S.M.S.), and the Humboldt Foundation (to R.W.). 


\section{References}

Agosti D (1990): Review and reclassification of Cataglyphis (Hymenoptera, Formicidae). J Nat Hist 24:1457-1505.

Anton S, Homberg U (1999): Antennal lobe structure; in Hansson BS (ed): Insect Olfaction. Berlin, Springer, pp 97-124.

-Arnold G, Masson C, Budharugsa S (1985): Comparative study of the antennal lobes and their afferent pathway in the worker bee and the drone (Apis mellifera). Cell Tissue Res 242:593-605.

-Berg BG, Almaas TJ, Bjaalie JG, Mustaparta H (1998): The macroglomerular complex of the antennal lobe in the tobacco budworm moth Heliothis virescens: specified subdivision in four compartments according to information about biologically significant compounds. J Comp Physiol A 183:669-682.

Beugnon G, Chagné P, Dejean A (2001): Colony structure and foraging behavior in the tropical formicine ant, Gigantiops destructor. Insect Soc 48:347-351.

Bisch-Knaden S, Wehner, R (2003): Local vectors in desert ants: context-dependent landmark learning during outbound and homebound runs. J Comp Physiol A 189:181-187.

-Bogner F, Boppré M, Ernst KD, Boeckh J (1986): $\mathrm{CO}_{2}$ sensitive receptors on labial palps of Rhodogastria moths (Lepidoptera: Arctiidae): physiology, fine structure and central projection. J Comp Physiol A 158:741-749.

-Brockmann A, Brückner D (2001): Structural differences in the drone olfactory system of two phylogenetically distant $A$ pis species, $A$. flore and $A$. mellifera. Naturwissenschaften 88:78-81.

Cerdá X (1988): La carrera nupcial de Cataglyphis iberica (Hymeoptera: Formicidae). Congr Iberico Entomol 3:511-514.

Collett M, Collett TS (2009): The learning and maintenance of local vectors in desert ant navigation. J Exp Biol 212:895-900.

Collett TS, Dillmann E, Giger A, Wehner R (1992): Visual landmarks and route following in desert ants. J Comp Physiol A 170:435442.

Collingwood CA (1985): Hymenoptera: Fam. Formicidae of Saudi Arabia. Fauna Saudi Arabia 7:230-302.

-Dillier FX, Wehner R (2004): Spatio-temporal patterns of colony distribution in monodomous and polydomous species of North African desert ants, genus Cataglyphis. Insect Soc 51:186-196.

-Fishilevich E, Vosshall LB (2005): Genetic and functional subdivision of the Drosophila antennal lobe. Curr Biol 15:1548-1553.

-Flanagan D, Mercer AR (1989): An atlas and 3-D reconstruction of the antennal lobes in the worker honey bee, Apis mellifera L. (Hymenoptera: Apidae). Int J Insect Morphol 18: 145-159.
Galizia CG, McIlwrath SL, Menzel R (1999a): A digital three-dimensional atlas of the honeybee antennal lobe based on optical sections acquired by confocal microscopy. Cell Tissue Res 295:383-394.

Galizia CG, Rössler W (2010): Parallel olfactory systems in insects: anatomy and function. Annu Rev Entomol 55:399-420.

Galizia CG, Sachse S, Rappert A, Menzel R (1999b): The glomerular code for odor representation is species specific in the honeybee Apis mellifera. Nat Neurosci 2:473-478.

Goll W (1967): Strukturuntersuchungen am Gehirn von Formica. Z Morph Ökol Tiere 59: 143-210.

Groh C, Rössler W (2008): Caste-specific postembryonic development of primary and secondary olfactory centers in the female honeybee brain. Arthropod Struct Dev 37:459468.

Groh C, Tautz J, Rössler W (2004): Synaptic organization in the adult honey bee brain is influenced by brood-temperature control during pupal development. Proc Natl Acad Sci USA 101:4268-4273.

Gronenberg W, Hölldobler B (1999): Morphologic representation of visual and antennal information in the ant brain. J Comp Neurol 412:229-240.

Guerenstein PG, Christensen TA, Hildebrand JG (2004): Sensory processing of ambient $\mathrm{CO}_{2}$ information in the brain of the moth Manduca sexta. J Comp Physiol A 190:707725.

-Haak U, Hölldobler B, Bestmann HJ, Kern F (1996): Species-specificity in trail pheromones and Dufour's gland contents of Camponotus atriceps and C. floridanus (Hymenoptera: Formicidae). Chemoecology 7:8593.

Hansson BS, Anton S (2000): Function and morphology of the antennal lobe: new developments. Annu Rev Entomol 45:203-231.

Hansson BS, Christensen TA, Hildebrand JG (1991): Functionally distinct subdivisions of the macroglomerular complex in the antennal lobe of the male sphinx moth Manduca sexta. J Comp Neurol 312:264-278.

Hildebrand JG, Shepherd GM (1997): Mechanisms of olfactory discrimination: converging evidence for common principles across phyla. Annu Rev Neurosci 20:595-631.

Hölldobler B, Wilson EO (1990): The Ants. Cambridge, Belknap Press of Harvard University Press.

-Homberg U, Christensen TA, Hildebrand JG (1989): Structure and function of the deutocerebrum in insects. Annu Rev Entomol 34: 477-501.

Hoyer SC, Liebig J, Rössler W (2005): Biogenic amines in the ponerine ant Harpegnathos saltator: serotonin and dopamine immunoreactivity in the brain. Arthropod Struct Dev 34:429-440.
Joerges J, Küttner A, Galizia CG, Menzel R (1997): Representation of odours and odour mixtures visualized in the honeybee brain. Nature 387:285-288.

Kelber C, Rössler W, Kleineidam CJ (2010): Phenotypic plasticity in number of glomeruli and sensory innervation of the antennal lobe in leaf-cutting ant workers (A. vollenweideri). Dev Neurobiol 70:222-234.

- Kelber C, Rössler W, Roces F, Kleineidam CJ (2009): The antennal lobes of fungus-growing ants (Attini): neuroanatomical traits and evolutionary trends. Brain Behav Evol 73: 273-284.

Kent KS, Harrow ID, Quartararo P, Hildebrand JG (1986): An accessory olfactory pathway in Lepidoptera: the labial pit organ and its central projections in Manduca sexta and certain other sphinx moths and silk moths. Cell Tissue Res 245:237-245.

Kent KS, Oland LA, Hildebrand JG (1999): Development of the labial pit organ glomerulus in the antennal lobe of the moth Manduca sexta: the role of afferent projections in the formation of identifiable olfactory glomeruli. J Neurobiol 40:28-44.

-Kirschner S, Kleineidam CJ, Zube C, Rybak J, Grünewald B, Rössler R (2006): Dual olfactory pathway in the honeybee, Apis mellifera. J Comp Neurol 499:933-952.

Kleineidam CJ, Obermayer M, Halbich W, Rössler W (2005): A macroglomerulus in the antennal lobe of leaf-cutting ant workers and its possible functional significance. Chem Senses 30:1-10.

Kleineidam CJ, Rössler R (2009): Adaptations in the olfactory system of social Hymenoptera; in Gadau J, Fewell J (eds): Organization of Insect Societies. Cambridge, Harvard University Press, pp 195-219.

Kuebler LS, Kelber C, Kleineidam CJ (2010): Distinct antennal lobe phenotypes in the leafcutting ant (Atta vollenweideri). J Comp Neurol 518:352-365.

Kühn-Bühlmann S, Wehner R (2006): Age-dependent and task-related volume changes in the mushroom bodies of visually guided desert ants, Cataglyphis bicolor. J Neurobiol 66: 511-521.

Lee JK, Altner H (1986): Primary sensory projections of the labial palp-pit organ of Pieres rapae L. (Lepidoptera: Pieridae). Int J Insect Morphol 15:439-448.

- Lenoir A, Querard L, Pondicq N, Berton F (1988): Reproduction and dispersal in the ant Cataglyphis cursor (Hymenoptera, Formicidae). Psyche 95:21-44.

Marsh AC (1985): Microclimatic factors influencing foraging patterns and success of the thermophilic desert ant, Ocymyrmex barbiger. Insect Soc 32:286-296. 
- Mustaparta H (1990): Chemical information processing in the olfactory system of insects. Physiol Rev 70:199-245.

- Nakanishi A, Nishino H, Watanabe H, Yokohari F, Nishikawa M (2010): Sex-specific antennal sensory system in the ant Camponotus japonicus: glomerular organizations of antennal lobes. J Comp Neurol 518:2186-2201.

- Nishikawa M, Nishino H, Misaka Y, Kubota M, Tsuji E, Satoji Y, Ozaki M, Yokohari F (2008): Sexual dimorphism in the antennal lobe of the ant Camponotus japonicus. Zool Sci 25: 195-204.

-Nishikawa M, Yokohari F, Ishibashi T (1995): Central projections of the antennal cold receptor neurons and hygroreceptor neurons of the cockroach Periplaneta americana. J Comp Neurol 361:165-176.

- Nishino H, Nishikawa M, Mizunami M, Yokohari F (2009): Functional and topographic segregation of glomeruli revealed by local staining of antennal sensory neurons in the honeybee Apis mellifera. J Comp Neurol 515: 161-180.

- Nishino H, Yamashita S, Yamazaki Y, Nishikawa M, Yokohari F, Mizunami M (2003): Projection neurons originating from thermo- and hygrosensory glomeruli in the antennal lobe of the cockroach. J Comp Neurol 455:40-55.

Radchenko AG (2001): The phylogeny and faunagenesis of the genus Cataglyphis (Hymenoptera, Formicidae) (in Russian). Ent Obozr 80:885-895.

Rospars JP (1988): Structure and development of the insect antennodeutocerebral system. Int J Insect Morphol 17:243-294.

-Rössler W, Kuduz J, Schürmann FW, Schild D (2002): Aggregation of F-actin in olfactory glomeruli: a common feature of glomeruli across phyla. Chem Senses 27:803-810.

- Rössler W, Randolph PW, Tolbert LP, Hildebrand JG (1999): Axons of olfactory receptor cells of transsexually grafted antennae induce development of sexually dimorphic glomeruli in Manduca sexta. J Neurobiol 38: 521-541.

Sachse S, Rappert A, Galizia CG (1999): The spatial representation of chemical structures in the antennal lobe of honeybees: steps towards the olfactory code. Eur J Neurosci 11: 3970-3982.
-Sandoz JC (2006): Odour-evoked responses to queen pheromone components and to plant odours using optical imaging in the antennal lobe of the honey bee drone Apis mellifera $L$. J Exp Biol 209:3587-3598.

Schmid-Hempel P (1983): Foraging Ecology and Colony Structure of Two Sympatric Species of Desert Ants, Cataglyphis bicolor and C. albicans; PhD Thesis, University of Zurich.

Smid HM, Bleeker MA, van Loon JJ, Vet LE (2003): Three-dimensional organization of the glomeruli in the antennal lobe of the parasitoid wasps Cotesia glomerata and C. rubecula. Cell Tissue Res 312:237-248.

Steck K, Hansson BS, Knaden M (2009): Smells like home: desert ants, Cataglyphis fortis, use olfactory landmarks to pinpoint the nest. Front Zool 6:5.

Steck K, Knaden M, Hansson BS (2010): Do desert ants smell the scenery in stereo? An Behav 79:939-945.

-Stieb SM, Muenz TS, Wehner R, Rössler W (2010): Visual experience and age affect synaptic organization in the mushroom bodies of the desert ant Cataglyphis fortis. Dev Neurobiol 70:408-423.

Vickers NJ, Baker TC (1997): Chemical communication in heliothine moths. VII. Correlation between diminished responses to pointsource plumes and single filaments similarly tainted with a behavioral antagonist. J Comp Physiol A 180:523-536.

Wehner R (1981): Verhaltensphysiologische, funktionsmorphologische und taxonomische Studien an zwei Arten der Cataglyphis albicans-Gruppe (Formicidae, Hymenoptera). Mitt Dtsch Ges Allg Angew Ent 3:214-217.

Wehner R (1983): Taxonomie, Funktionsmorphologie und Zoogeographie der saharischen Wüstenameise Cataglyphis fortis (Forel 1902) stat. nov. Senckenbergiana Biol 64:89132.

Wehner R (1986): Art Charakterisierung von Cataglyphis diehlii und C. rubra. Jb Akad Wiss Lit Mainz 86:108-111.

Wehner R (1987): Spatial organization of foraging behavior in individually searching deser ants, Cataglyphis (Sahara Desert) and Ocymyrmex (Namib Desert); in Pasteels JM, Deneubourg JL (eds): From Individual to Collective Behavior in Social Insects. Basel, Birkhäuser, pp 15-42.
Wehner R (2003): Desert ant navigation: how miniature brains solve complex tasks. J Comp Physiol A 189:579-588.

Wehner R, Harkness RD, Schmid-Hempel P (1983): Foraging strategies in individually searching ants, Cataglyphis bicolor (Hymenoptera: Formicidae). Akad Wiss Lit Mainz, Abh Math Naturwiss KI. Stuttgart, Gustav Fischer.

Wehner R, Meier C, Zollikofer C (2004): The ontogeny of foraging behaviour in desert ants, Cataglyphis bicolor. Ecol Entomol 29:240250.

Wehner R, Müller M (2006): The significance of direct sunlight and polarized skylight in the ant's celestial system of navigation. Proc Natl Acad Sci USA 103:12575-12579.

Wehner R, Räber F (1979): Visual spatial memory in desert ants, Cataglyphis bicolor (Hymenoptera: Formicidae). Experientia 35:15691571.

Wehner R, Srinivasan MV (2003): Path integration in insects; in Jeffery KJ (ed): The Neurobiology of Spatial Behaviour. Oxford, Oxford University Press, pp 9-30.

Wehner R, Wehner S, Agosti D (1994): Patterns of biogeographic distribution within the bicolor species group of the North African desert ant, Cataglyphis Foerster (1850). Senckenbergiana Biol 74:163-191.

Wittlinger M, Wehner R, Wolf H (2006): The ant odometer: stepping on stilts and stumps. Science 312:1965-1967.

Wolf H, Wehner R (2000): Pinpointing food sources: olfactory and anemotactic orientation in desert ants, Cataglyphis fortis. J Exp Biol 203:857-868.

Wolf H, Wehner R (2005): Desert ants compensate for navigation uncertainty. J Exp Biol 208:4223-4230.

Zube C, Kleineidam CJ, Kirschner S, Neef J, Rössler W (2008): Organization of the olfactory pathway and odor processing in the antennal lobe of the ant Camponotus floridanus. J Comp Neurol 506:425-441.

Zube C, Rössler W (2008): Caste- and sex-specific adaptations within the olfactory pathway in the brain of the ant Camponotus floridanus. Arthropod Struct Dev 37:469-479. 